functional groups in a latent, less reactive form: in the piperidine precursor of quinine, an eventual $\varepsilon$-aminoheptanoic acid system is constructed by the cleavage of a 2-methylcyclohexanone, a chemically less reactive, and thus more easily controllable system.

The modern era of concern for stereochemistry started in the period 1950-1955, a period which saw the development of stereospecific, or highly stereoselective, syntheses of morphine, cantharidin, cortisone, cedrol and strychinine. These syntheses were all carried out without taking advantage of the enormous help, just becoming available, of Barton's principles of conformational analysis, but they are important because they represent the first successful efforts to take stereochemistry explicitly into account during the process of synthesis planning. This may seem an obvious prerequisite to a successful synthesis, but one need only read the highly imaginative, though largely inconclusive, series of some sixty papers on steroid "synthesis" by Robinson and his collaborators to see the staggering efforts which could be made to reach synthetic targets (steroids in this case), without any concern for the need to control the relative arrangement of the relevant atoms in space. When one considers that without such control, the connectivity implied by the two-dimensional structure of cholesterol represents 256 different substances, only one of which is cholesterol, it is no wonder that these efforts, brilliant as they sometimes were, remained largely abortive.

Although Woodward's 1951 steroid synthesis was only partially stereoselective in contrast to the cortisone synlthesis (by $\mathrm{L}$. H. Sarett) referred to above, it was nevertheless highly influential because it against used the structural simplification made possible by a temporary ring: a cyclohexene ring serves as the source of the steroid D-ring via its cleavage and cyclization to a more functional cyclopentene aldehyde. One also sees here an illustration of another important principle of many Woodward syntheses: the carbon framework is constructed as rapidly as possible, leaving some function (e.g. double bond) which will allow eventual structural adjustments.

It is with the synthesis of strychnine, in 1954, that Woodward began a series of classically elegant syntheses which have not yet been surpassed. In addition to strychnine, they are those of reserpine (1956), of chlorophyll (1960) and of the "western half" of vitamin $B_{12}$ (1972). In the strychnine construction, the ubiquitous ring element, placed in the $\alpha$-position of the indole ring of tryptamine, is a dimethoxybenzene ring which is here a latent 1,4 butadienedicarboxylic (muconic) ester system, in a much less reactive form. Before that transformation, however, that same ring is brilliantly used to ensure that an intramolecular cyclization via an iminium salt occurs at the $\beta$-position of an indole ring. The synthetic use of a dimethoxybenzene ring as a precursor of a muconic acid illustrates an aspect of the Woodward mastery which has been referred to previously: the cleavage of an ortho-dimethoxybenzene to a muconic acid had been stored in Woodward's memory since he had noticed its use by Speyer in the degradation of codeine. He was able to recall it just when it would be most dramatically useful.

In the synthesis of strychnine, details of oxidation states were consciously held in the background because of the great structural simplification thus allowed in the construction of the framework. This approach is further refined in the next great synthesis, that of reserpine, in which full and impressive use is made, for the first time, of Barton's conformational principles. In that synthesis, we have, once again, the use of a cyclohexene ring as a surrogate for an eventual aldehydo-ester. We also see here the dramatic simplification produced by the use of a double bond as the precursor of the monomethyl ester of a 1,2-glycol. There were, a priori, four possible such systems which might result from the cyclohexene double bond. Woodward had acquired, by that time, extraordinary confidence in his ability to find some way to make molecules dance to his tune: he felt that something might well happen during the synthesis, which would solve this potentially vexing problem. $\mathrm{He}$ was not disappointed. Only someone with Woodward's ability to deduce structures from a combination of limited spectral data and mechanistic insight could possibly have capitalised on the remarkable chemical events which provided a solution to the problem. Seldom has it been more true that "chance favors the prepared mind."

Chlorophyll and the "western half" of vitamin $B_{12}$ will end this broad sketch. In the synthesis of the former, it is still notable that a problem in producing the required regiochemistry was solved by selecting an aminoethyl group as precursor of an eventually required vinyl substituent, and using it in temporary ring formation with a pyrrole aldehyde. Again, the very difficult problem of introducing the two so-called "extra" hydrogens specifically in one of four pyrrole rings was solved, in a unique manner, by a sequence involving cyclization followed by cleavage.

Finally, when we come to the $B_{12}$ synthesis of 1972 , we are treated to a pyrotechnic display of appearing and disappearing rings which are ued here to achieve control of almost all the asymmetric centers in the molecule. A propionic acid chain arises from the remains of an anisole ring, and another one from a temporarily constructed cyclohexene. A $\delta$-ketoacid originates from the cleavage of a cyclopentene; an aminoacid system is born from a cyclopentanone, as yet further rings make their tightly orchestrated entrances and exits from the $B_{12}$ stage: a grand final tribute to the power of this approach to synthesis.

I referred at the very beginning to the great impact that Woodward had on all who associated with him. This was nowhere more obvious than in the celebrated "problem seminars" in which Woodward was always willing to take on all those who cared to match wits and deductive skills with him. It was not just the graduate students and postdoctoral associates who benefitted from contact with Woodward's logical approach to all chemical problems: an impressive number of papers by celebrated chemists all over the world (Arigoni, Bartlett, Barton, Bloch, Djerassi, Eschenmoser, Gates, Inhoffen, Jeger, Klyne, Prelog, Wilkinson, Winstein, Witkop. . .) have Woodward as a coauthor, obvious testimony to the insights that were gained by discussions with him.

Woodward would not have been human had he not enjoyed the attention he commanded. He relished keeping audiences enthralled for hours with a lecture in which he obviously savoured highlighting the already brilliant work he was describing by using meticulously drawn formulas, dramatically enhanced by the controlled use of colored chalk, further to emphasize the image of one in total command of his environment. He was not above playing along with the sensationalism of the media: "That is what the public wants of its heroes"; and he had no doubt that he had earned the right to special recognition at every level. One anecdote, perhaps, sums up the view he had of his rightful place in the world: A new guard at Harvard had just told Woodward that his (blue) car could not be left where he had placed it. "Why is that?" said Woodward. "Your name is not on the list," said the guard. "It isn't?" said Woodward, turning back toward the guard without stopping, "well . . . put it there!" One thing is certain, Woodward's place in chemical history is permanently reserved.

Gilbert Stork

\section{G.S. Forbes}

George Shannon Forbes, Emeritus Professor of Chemistry at Harvard University, died on 24 June 1979 in his home in Cambridge, Massachusetts.

Born on 17 March 1882 in Boston, Massachusetts, Forbes' interest in science was awakened at the age of eight, by a lecture on pendulums given by his father, George Fairfield Forbes, who was a pioneering teacher of experimental science at the prestigious Roxbury Latin School. But when young Forbes graduated from that same school he aspired to a career as a professor of classics. During his sophomore year at Harvard College, he reports, in a course on qualitative analysis the 
challenge of numerous "diabolical mixtures ... aroused my combative instincts, and provided real excitement . . . Gradually the classics were supplanted by a new enthusiasm. Then followed a truly decisive event. Professor Charles R. Sanger told me that next year's class would be larger than usual. Would I serve as assistant without stipend? Of course I said 'Yes,' and so, not long after my eighteenth birthday, I became a duly appointed officer of instruction in Harvard University, continuing on through senior year . . . Ten years later, this adventure had a direct influence on my fortunes. When Professor Sanger's health became impaired, I was asked to collaborate with him. Upon his death, I took charge of qualitative analysis, and thus my feet became planted upon the academic ladder."

By that time Forbes had long since passed from undergraduate to graduate work at Harvard. Under the direction of T.W. Richards, later to become America's first Nobel laureate in the sciences, Forbes completed in 1905 a doctoral thesis on the electrochemistry of amalgams. He then went on with Richards to a revision of the atomic weights of nitrogen and silver. The keystone of this endeavour was a meticulous redetermination of the exact weight of pure silver nitrate yielded by one gram of pure silver, and the result thus obtained still stands unchallenged (good to $0.002 \%$ ). But this notable first was also Forbes' last investigation of atomic weights. Most of his nearly 100 research publications deal with solution physical chemistry, especially electrochemistry, and with photochemistry, in which field he was an American pioneer.

Forbes' life and career were wholly centered on Boston and Cambridge Massachusetts. To be sure, he spent 1906-07 at the universities of Leipzig and Berlin, followed by two years as associate in chemistry at Bryn Mawr College. But in 1909 he returned as instructor in physical chemistry to Harvard University, and here he stayed to become Professor in 1926, Chairman of the Chemistry Department in the difficult years 1944-47, and Emeritus Professor in 1948. Even then Forbes' academic career continued for 8 years more Northeastern University and, still persevering as a consultant to chemical industry, inuing as a consultant to chemical industry, he continued laboratory work with his own hands until the age of 90 . Triumphant over the hazards besetting the experimental chemist, he was at 97 the oldest living graduate of Roxbury Latin. He outlived his cherished wife of 60 years, née Marie Louise Hersey, but is survived by a son, a daughter, and four grandchildren.

Born into a family where father, mother (née Elizabeth Shannon), aunts, and uncles were all teachers, Forbes came naturally to that vocation. His teaching career spanned 60 years and some 9000 students. A highlyorganized lecturer who wrote everything out in a well-ordered display on the black- board, Forbes was also a willing spontaneous commentator on the illuminating aberrations of the innumerable lecture experiments he dextrously produced. He was in 1951 the deservedly first recipient of the James Flack Norris Award for outstanding achievement in the teaching of chemistry.

Forbes was a New Englander through and through: sturdy, spare, independent, reserved, and patient. But beneath the somewhat austere exterior lay abundant dry wit, and a human warmth that engaged many friends. An attractively multidimensional person, Forbes was a photographer of professional competence, an energetic hiker and climber (long the faculty adviser of the Harvard Mountaineering Club), and an avid musician who lent his (double bass) voice to many local choruses. His high sense of responsibility found expression in a lifetime of devoted service to his science, his Department, his University, and his Church. His was a New England life of little showiness but admirable substance.

Leonard K. Nash

\section{Sir Frank Fraser Darling}

THE death of Sir Frank Fraser Darling on 22 October 1979 at the age of 76 will be greatly regretted by naturalists and wildlife conservationists in many parts of the world. Although he only came to wide public notice in Britain when he gave the 1969 Reith Lectures, he had made outstanding contributions to the understanding of wild animals and of the countryside over a period of some 50 years, and his counsels were much sought after in America and elsewhere in the 1950s and ' 60 s, when his own countrymen paid less attention to his opinions.

He started work in 1924 as an agriculturalist. After three years on the staff of the Buckinghamshire County Council he went as a research student to the Institute of Animal Genetics in the University of Edinburgh. He was appointed Chief Officer of the Imperial Bureau of Animal Genetics in Edinburgh in 1930, under the late Professor F.A.E. Crew, and he remained in that post until 1933. He then gave up this urban, academic life, and began his work, often under conditions of considerable austerity, in the highlands and islands of Scotland. He held Carnegie and Rockefeller research fellowships, and was Director of the West Highland Survey from 1944-50, but this was a precarious existence with little of the security scientific workers expect today. However, he was able to spend his time in the field really getting to understand the conditions of his harsh environment.

During this period he wrote many books such as $A$ Herd of Red Deer and $A$ Naturalist on Rona, vividly describing his observations and his experience. His Bird Flocks and the Breeding Cycle initiated a new field of research. These books had a considerable appeal to other naturalists and to discerning scientists, but were dismissed as too "popular" by the educational establishment, and so did not receive the recognition his admirers felt they deserved. He was bitterly disappointed at the reception given by "the authorities" to his West Highland Survey. His apparently eccentric behaviour and unconventional way of life (something which would be thought normal today) also prevented him from being properly appreciated as an observer and an ecologist in academic circles. At a time when laboratory studies of animal cells or isolated organs were considered more scientific than those involving whole animals in the wild, and when even meticulous observation was considered inferior to experimentation, it is not surprising tht he felt he was not properly appreciated.

He did return to academic life for a few years when he was appointed Senior Lecturer in Ecology and Conservation at Edinburgh University in 1953 at the age of nearly 50 . He was also invited by the Nature Conservancy in Britain, then a young and developing organisation, to advise them in their studies on Red Deer. This work, and his earlier observations, enabled the Conservancy to introduce a proper management policy particularly to the island of Rhum, where within the National Nature Reserve populations of deer were maintained at optimum levels by a careful culling policy. However, Fraser Darling increasingly found tht his views were being taken more seriously in the United States of America, and in 1959 he accepted an invitation from Dr Fairfield Osborn to become Vice President of the Conservation Foundation in Washington DC. His studies of the caribou in Alaska with Dr Starker Leopold, and of the larger mammals in Norther Rhodesia and other African territories did much to consolidate his international reputation.

While in the United States he was impressed with the work done there in setting up National Parks, and he was critical of other countries, including his own, for their slowness in following the American example. However, he praised the British Nature Conservancy for their work, with limited resources, and particularly for establishing several valuable reserves in Scotland.

As already indicated, it was not until 1969 that Britain recognised his contribution to conservation. 1970 had been designated European Conservation Year, and plans to that end were being made by a committee under the patronage of HRH Prince Philip. It was suggested that the 1969 Reith Lectures of the British Broadcasting Corporation should be devoted to some suitable ecological topic, and that they should act as a curtain raiser. 